3. Денисенко, В. В. ПИД-регуляторы: принципы построения и модификации [Текст] / В. В. Денисенко // CTA. - 2006. - № 4. - C. 66-74.

4. Волуева, О. С. Компенсация эффекта интегрального насыщения регулятора в системе управления уровнем металла в кристаллизаторе МНЛЗ [Текст] / О. С. Волуева // Наукові праці ДонНТУ. Серія: обчислювальна техніка та автоматизація. - 2013. № 2 (25). - C. 13-20.

5. Ковриго, Ю. М. Математическое моделирование систем автоматического регулирования с учетом ограничений на управление в пакете Matlab [Текст] / Ю. М. Ковриго, Б. В. Фоменко, И. А. Полищук // Автоматика. Автоматизация. Электротехнические комплексы и системы. - 2007. - № 2. -С. 21-28.

6. Дьяконов, В. П. Matlab 6.5 SP1/7.0 Simulink 5/6. Основы применения [Текст] / В. П. Дьяконов. М.: СОЛОН-Пресс, 2005. - 806 с.

\section{References}

1. Murray, R. M., Li, Z., Sastry, S. S. (2006). A Mathematical Introduction to Robotic Manipulation. CRC Press, 4-th ed, 474.
2. Astrom, K. J. (2014). Advanced PID control. ISA (The Instrumentation, Systems, and Automation Society), 662.

3. Denisenko, V. V. (2006). PID-regulyatoryi: printsipyi postroeniya i modifikatsii [PID controllers: principles of construction and modification]. STA, 4, 66-74.

4. Volueva, O. S. (2013). Kompensatsiya effekta integralnogo nasyischeniya regulyatora $\mathrm{v}$ sisteme upravleniya urovnem metalla $\mathrm{v}$ kristallizatore MNLZ [Integral saturation effect compensation in controller for automation system of metal level in the continuous caster mold]. Proceedings Donetsk National Technical University, series: Computer Science and Automation, 2 (25), 13-20.

5. Kovrigo, Yu. M. (2007). Matematicheskoe modelirovanie sistem avtomaticheskogo regulirovaniya $\mathrm{s}$ uchetom ogranicheniy na upravlenie $\mathrm{v}$ pakete Matlab [Mathematical modeling of automatic control systems, taking into account limitation of control in Matlab program]. Automatics . Automatization . Electrical equipment and systems, 2, 21-28.

6. Dyakonov, V. P. (2005). Matlab $6.5 \mathrm{SP} 1 /$ 7.0 Simulink 5/6. Osnovyi primeneniya [Matlab 6.5 SP1 / 7.0 Simulink 5/6. Basic Usage]. Moscow: SOLON-Press, 806.

Рекомендовано до публікації д-р техн. наук, проф. Ладанюк А. П. Дата надходження рукопису 23.10.2014

Кроніковський Дмитро Олегович, доцент, кандидат технічних наук, кафедра Автоматизації процесів управління, Національний університет харчових технологій, вул. Володимирська, 68, м. Київ, Україна, 01601

E-mail: kronikovsky@gmail.com

УДК 677.014.84

DOI: $10.15587 / 2313-8416.2014 .28686$

\title{
ОЦЕНКА КАЧЕСТВА ПОЛИЭФИРНЫХ ВОЛОКОН (НИТЕЙ) МЕТОДОМ ПОЛЯРИЗАЦИОННОЙ МИКРОСКОПИИ
}

\section{(C) Г. А. Скрипко}

Представлен инновационный подход к контролю качества полиэфирных волокон и нитей, который предусматривает проведение анализа внутренней структуры волокнообразующего полимера. Показано, что использование метода поляризационной микроскопии дает возможность выявлять пороки внутренней структуры полиэфирных волокон (нитей), а также вести контроль на соответствие качества волокнообразующего полимера образиу.

Ключевые слова: полиэфирное волокно, поляризационная микроскопия, внутренняя структура полимера, интерферениионная картина, образецฺ.

Innovative approach in the quality control of polyester fibers and yarns, which provides conduction of analysis of inner structure of fiber-forming polymer, is represented. The fact that the usage of polarization microscopy method gives an opportunity to reveal the faults of inner structure of polyester fibers (yarns) and also to conduct the control concerning correspondence of quality of fiber-forming polymer to the sample is shown.

Keywords: polyester fiber, polarization microscopy, inner structure of polymer, interference pattern, sample.

\section{1. Введение}

Проблема, рассматриваемая в статье, актуальна для текстильного сектора. Решение проблемы связано с усовершенствованием оценки качества полиэфирных (ПЭ) волокон и элементарных нитей.

Необходимость в инновационном подходе к контролю качества химических волокон и нитей, в частности ПЭ, связана с ежегодным увеличением их объема производства. По данным маркетингового анализа [1] в 2011 году мировое производство всех видов волокон составило 84,1 млн.т., из них 51 млн. т. приходится на химические волокна и нити. Среди химических волокон доминирующее положение попрежнему занимают ПЭ волокна и нити - 39 млн. т. Наиболее высокий прирост производства этого вида продукции отмечен в Турции - $29 \%$, США - $20 \%$, Китае - $16 \%$, Ю. Корее - $14 \%$, Японии - $12 \%$ [2]. 


\section{2. Постановка проблемы}

Предприятия, вырабатывающие и использующие в своем производстве текстильное сырье, при оценке качества волокон и нитей, в том числе и ПЭ, руководствуются нормами, утвержденными государственными стандартами. Нормативными показателями являются: линейная плотность, удельная разрывная нагрузка, удлинение, влажность, длина штапелек, степень извитости и др. Отбраковка, основанная лишь на выявлении внешних пороков волокна или нити, измерении их физикомеханических показателей, являющихся общей характеристикой полимера, не позволяет в полной мере оценить качество продукции. Возможность выявления скрытых дефектов полимера позволит расширить рамки контроля и гарантировать долговечность волокон и нитей, а следовательно и продукции, изготавливаемой из них.

Таким образом, разработка метода, позволяющего экспрессивно выявлять внутренние пороки волокнообразующего полимера на разных стадиях технологического процесса, а также проводить оценку качества готовой продукции актуальна.

\section{3. Литературный обзор}

Анализ источников информации по оценки качества текстильного сырья и материалов показал, что комплексная оценка качества волокон включает в себя оптические методы, в том числе поляризационную микроскопию [3, 4].

Комплектация современных поляризационных микроскопов позволяет ускорить процесс идентификации единичных волокон по виду, не разрушая их. Для этой цели разработаны методики [5-7], согласно которых видовая принадлежность волокон определяется по интерференционной картине, наблюдаемой на волокне в поляризационном свете. Отличие волокон по рисунку и цвету интерференционного окрашивания объясняется индивидуальными особенностями их внутренней структуры.

Известно [8], что оптические свойства волокнообразующего полимера, отражают особенности его молекулярного и надмолекулярного строения. Большинство химических и натуральных волокон оптически анизотропны и отличаются по показателю двойного лучепреломления. Кроме того они отличаются по однородности внутренней структуры. Исследованием полиэтилентерефталата и целлюлозы натуральных волокон рентгеноструктурным анализом доказано [9, 10], что полимер волокна образован з разных по плотности структур. Более плотные, упорядоченные, трехмерные структуры отнесены к кристаллическим, неупорядоченные и разрыхленные - к аморфным. Кроме указанных фазовых областей обнаружены структуры с промежуточными ступенями упорядоченности макромолекул. Однако из-за нечеткости границ фазовых областей разделить их точно в объеме полимера, используя рентгеноструктурный анализ, не удалось. Отсутствие четких границ между фазовыми областями в полимере теоретически объясняется тем, одна молекулярная цепь проходит через несколько областей порядка и беспорядка, при этом переход от упорядоченного к менее упорядоченному состоянию и наоборот, происходит постепенно [11]. Наблюдаемое на волокне в поляризационном свете интерференционное окрашивание рисунка также указывает на неоднородность структуры волокнообразующего полимера. Разнообразие рисунков и цветов выделенных участков указывает на существование в полимере разных по плотности и размерам фазовых областей. Кроме того разнообразие цветов окрашенных областей, позволяет сделать предположение о существовании в полимере большего, чем три, количества фаз.

Целью проведенной работы являлось установление приемлемости метода поляризационной микроскопии для оценки качества полиэфирных волокон (нитей) и выявления скрытых пороков волокнообразующего полимера.

Для достижения поставленной цели необходимо было решить следующие задачи:

1. Провести анализ интерференционной картины, наблюдаемой в поляризационном свете на ПЭ волокнах и элементарных нитях, отличающихся по ассортименту;

2. Установить характер взаимосвязи рисунка и цвета интерференционного окрашивания и с показателями качества.

4. Установление признаков, характеризующих качество внутренней структуры полиэфирных волокон (нитей), методом поляризационной микроскопии

В качестве объектов исследования были выбраны полиэфирные волокна и элементарные нити, отличающиеся по ассортименту, также волокна и нити, имеющие износ.

Исследование волокон и элементарных нитей проводилось в поле зрения поляризационного микроскопа «Полам Л-213» при скрещенных анализаторе и поляризаторе, увеличении объекта в 360 раз. Для получения изображения в цифровом формате использовалась цифровая видеокамера и компьютерная программа "Эксперт". Цифровое изображение фиксировалось в формате ВМР.

Интерференционная картина на ПЭ волокнах (нитях) наблюдалась без применения компенсатора.

По результатам анализа интерференционной картины, наблюдаемой на изображении исследуемых образцов, волокна были разделены на четыре группы и восемь подгрупп. Разделение на группы и подгруппы проводилось по двум признакам рисунку и цвету интерференционного окрашивания.

Групnа I. Симметричные продольные полосы центральная полоса широкая, крайние узкие (красного и желтого цветов).

Дифференциация на подгруппы проводилась по цвету и однородности окрашивания центральной полосы. 
цвета;

1 - однородное окрашивание коричневого

2 - однородное окрашивание зеленого цвета;

3 - неоднородное окрашивание - появление пятен или участков зеленого цвета на полосе коричневого цвета;

4 - неоднородное окрашивание - появление пятен или участков красно-коричневого цвета на полосе зеленого цвета;

5 - неоднородное окрашивание - на полосе красного цвета пятна зеленого цвета;

6 - однородное окрашивание - красного или красно-фиолетового цвета.

В ходе анализа отмечено, что признаки 1-4 подгрупп наблюдались на штапельных волокнах цилиндрической формы, слабо и нормально матированных, а также на нематированных, профилированных нитях с треугольной формой поперечного сечения (при условии, что интерференционная картина наблюдалась на одной из граней фрагмента нити). Признаки характерные для 5 подгруппы наблюдались на волокнах и нитях, имеющих деструкцию, например, неравномерность по толщине, а также на профилированных нитях с гантелевидной формой поперечного сечения. Признаки 6 подгруппы наблюдались на волокнах и нитях толщиною меньше 15 мкм.

Группа II. Несимметричные продольные полосы зеленого, коричневого или коричневокрасного цветов.

Признаки характерные для этой группы наблюдались на профилированных нитях с треугольной формой поперечного сечения (нематированных, средне и сильно матированных).

Группа III. Косые полосы коричневого, коричневокрасного и зеленого цветов.

Интерференционная картина характерная для образцов, сгруппированных в III группу, наблюдалась на волокнах и нитях, подвергавшихся механическому и термическому воздействию крутка и термофиксация (в ходе технологического процесса или при производстве пряжи, текстильного полотна). Было сделано предположение, что угол наклона полос, их площадь и цвет зависят от степени внешнего механического и термического воздействия.

Группа IV. Пестрое окрашивание.

Пестрое окрашивание наблюдалась на текстурированных нитях, нитях материала прошедшего термофиксацию, нитях и волокнах толщина которых не превышает 12 мкм, а также на волокнах имеющих износ.

Для волокон 1-ой подгруппы характерно разноцветное окрашивание участков по длине волокна. Для волокон 2-ой подгруппы - пестрое окрашивание в виде пятен небольших площадей.

На основе анализа, проведенных исследований, было сделано заключение, что формирование особенностей внутренней структуры волокнообразующего полимера происходит на разных этапах технологического процесса и модернизации продукции. Влияние этих процессов отображается в интер- ференционной картине. Износ текстильного материала вносит свои коррективы в рисунок и окраску интерференционной картины. Ниже представлены изображения интерфе-ренционной картины (рис. 1-4), наблюдаемой на штапельных волокнах, извлеченных с разных видов тканей.

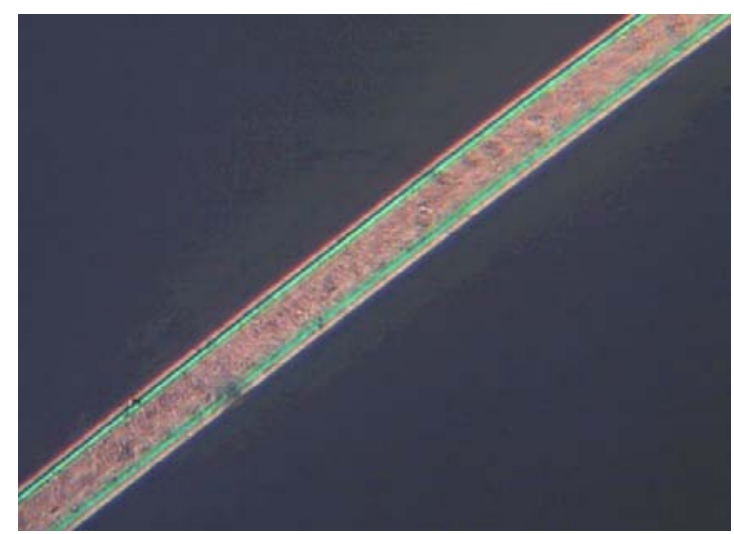

Рис. 1. Цифровое изображение

интерференционной картины, наблюдаемой на участке ПЭ волокна, отнесенного по классификации к I группе, 1 подгруппе

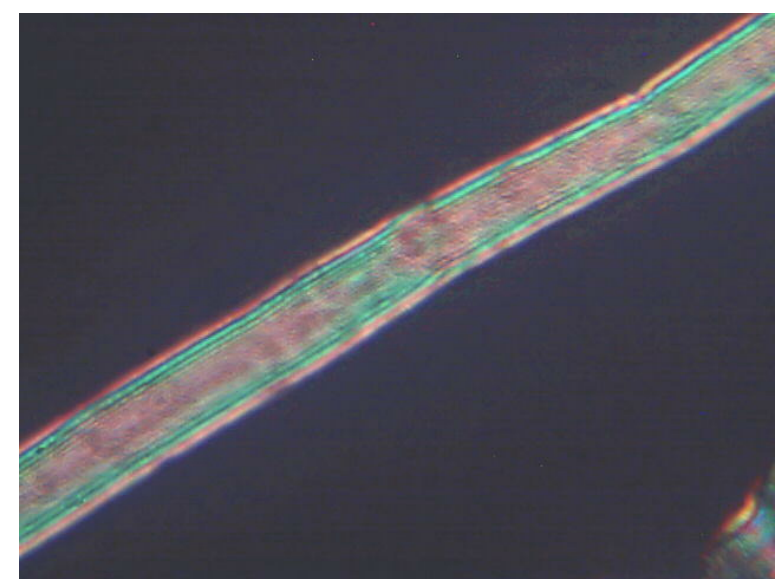

Рис. 2. Цифровое изображение интерференционной картины, наблюдаемой на участке ПЭ волокна, отнесенного по классификации к I группе, 3 подгруппе

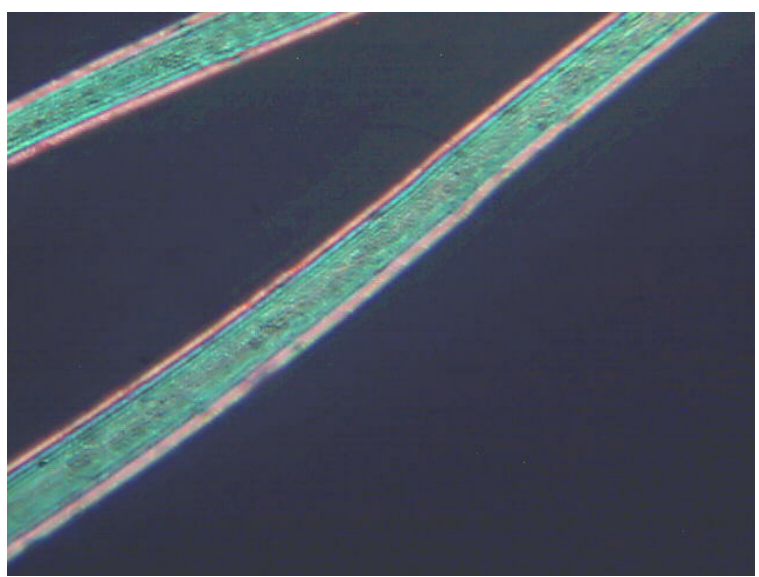

Рис. 3. Цифровое изображение интерференционной картины, наблюдаемой на участке ПЭ волокна, отнесенного по классификации к I группе,

2 подгруппе 


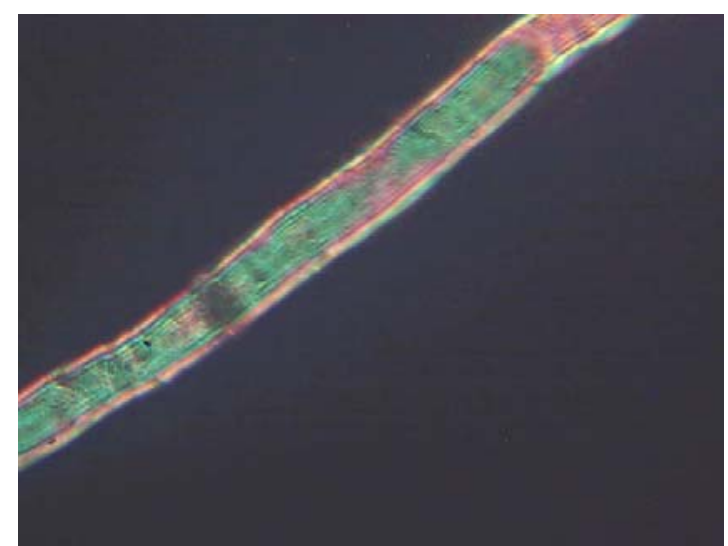

Рис. 4. Цифровое изображение интерференционной картины, наблюдаемой на участке ПЭ волокна, отнесенного по классификации к I группе, 4 подгруппе
Известно [12], что со снижением однородности структуры волокна прочность его уменьшается. Для проверки взаимосвязи структурной неоднородности ПЭ волокон и равномерности интерференционного окрашивания, была измерена прочность штапельных волокон, ранее отнесенных к первой группе. Показатель прочности определялся на модуле системы типа Uster HVI, предназначенном для этой цели. Полученные данные представлены в табл.1. Анализ данных табл. 1 подтвердил предположение о том, что равномерность окрашивания ПЭ волокон в поляризационном свете, является характеристикой однородности структуры и пропорционально связана с показателем прочности.

Таблица 1

Удельная разрывная нагрузка штапельных ПЭ волокон

\begin{tabular}{|c|c|c|c|c|}
\hline \multicolumn{5}{|c|}{ Группа и подгруппа ПЭ волокон } \\
\hline I.1 & I.2 & I.3 & I.4 & I.5 \\
\hline \multicolumn{5}{|c|}{ Удельная разрывная нагрузка, сH/текс } \\
\hline 44,3 & 40,6 & 34,7 & 30,2 & 28,7 \\
\hline
\end{tabular}

Примечание - систематическая погрешность измерений не превышала $1,5 \mathrm{cH} /$ текс.

Характер взаимосвязи цвета интерференционного окрашивания с оптической плотностью определялся по величине разности хода двойного лучепреломления. Для этого использовалась таблица
Ньютона [8] и номограмма Мишель-Леви [13]. Установленный для каждого цвета оптический показатель представлен в (табл. 2).

Таблица 2

Показатель преломления окрашенного участка интерференционного рисунка, наблюдаемого на ПЭ волокнах в поляризационном свете

\begin{tabular}{|c|c|c|c|c|c|}
\hline \multicolumn{7}{|c|}{ Цвет интерференционного окрашивания } \\
\hline $\begin{array}{c}\text { Коричнево- } \\
\text { красный }\end{array}$ & Зеленый & $\begin{array}{c}\text { Фиолетово- } \\
\text { красный }\end{array}$ & Желтый & Синий & Фиолетовый \\
\hline \multicolumn{7}{|c|}{ Показатель преломления окрашенного участка } & 0,05 & 0,045 \\
\hline 0,16 & 0,13 & 0,09 & 0,07 & 07 \\
\hline
\end{tabular}

На основе взаимосвязи цвета интерференционного окрашивания с уменьшением показателей качества ПЭ волокон (табл. 1, 2) предложена схема, показывающая снижение качества ПЭ волокон (нитей) относительно интерференционной окраски их участков:

Коричнево-красный $\rightarrow$ зеленый $\rightarrow$ краснофиолетовый $\rightarrow$ жселтый $\rightarrow \rightarrow$ синий $\rightarrow$ фиолетовый

Перспективным в данном направлении является проведение количественного анализа цифрового изображения интерференционной картины участка волокна (нити) с помощью компьютерной программы, путем выделение цветовых регионов и расчета их относительной площади к общей площади участка.

\section{5. Апробация результатов исследований}

Апробация по оценке качества ПЭ волокон (нитей) по показателям, характеризующим его внутреннюю структуру, проводилась на изделиях отобранных в ходи инспекционной проверки детских товаров. Отборка проводилась сотрудниками «Інспекції 3 питань захисту прав споживачів у Миколаївській області ДІ України» в торговых точках г. Николаева.

На экспертизу были направлены носки детские «Топко», арт. 3089 (размер -12), производитель ТОВ «ДТ ТЕРКУРІЙ» (Украина г. Тернополь) и носки детские (размер - 12), производитель Компания «Ориентекс» (Гонконг, импортер Украина, г. Киев).

В процессе исследования крученой и текстурированной нитей трикотажа детских носок Китайского производителя установлено, что крученая пряжа на 100 \% состоит из ПЭ волокон (рис. 5), комплексная текстурированная нить также однородна - 100 \% ПЭ. При исследовании носок, производителем которых является ТОВ «ДТ ТЕРКУРІЙ» установлено, что крученая пряжа наряду с хлопковыми волокнами содержит $25 \%$ 
полиэфирных волокон (рис. 6). Текстурированная нить $-100 \%$ ПЭ.

Цифровое изображение интерференционной картины участков полиэфирных волокон извлеченных из пряжи обоих изделий дано на рис. 5, 6 .

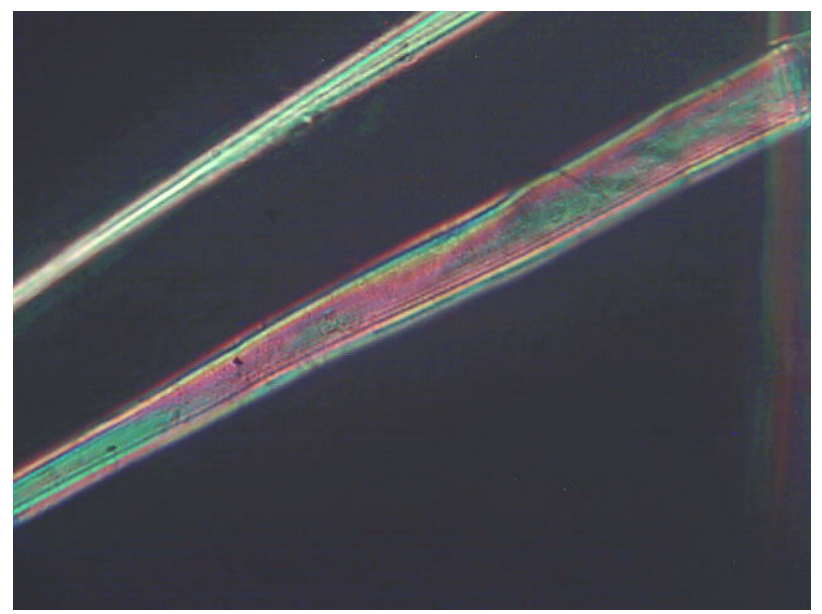

Рис. 5. Цифровое изображение

интерференционной картины, наблюдаемое на участке ПЭ волокна, извлеченного из крученой пряжи изделия Компании «Ориентекс» (Гонконг, импортер Украина, г. Киев)

Проведение сравнительного анализа интерференционной картины полиэфирных волокон, входящих в состав пряжи носок Китайского производителя с интерференционной картиною образца (рис. 2), позволило отнести их к волокнам низкого качества.

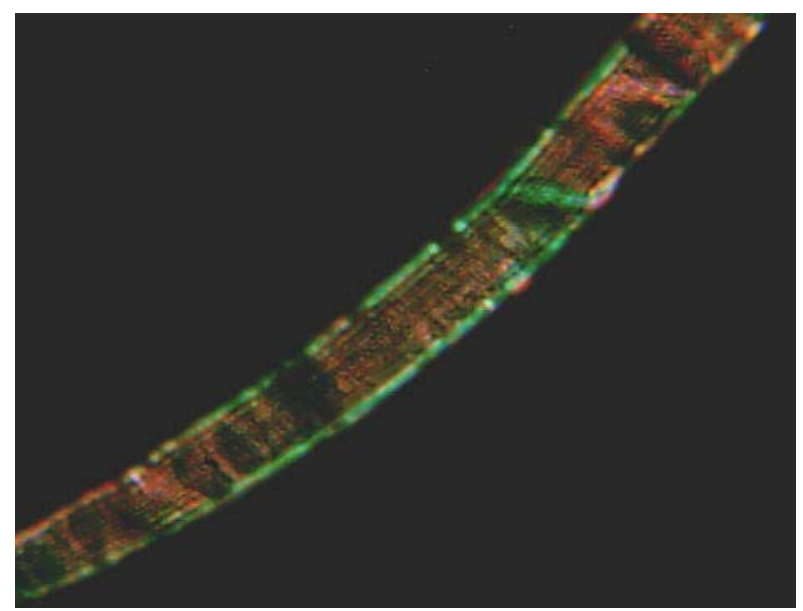

Рис. 6. Цифровое изображение

интерференционной картины, наблюдаемое на участке ПЭ волокна, извлеченного из крученой пряжи изделия ТОВ «ДТ ТЕРКУРІЙ» (Украина г. Тернополь)

Сравнительный анализ интерференционной картины полиэфирных волокон, входящих в состав пряжи носок Украинского производителя с интерференционной картиною образца (рис. 1), позволил выявить пороки их внутренней структуры, а именно - наличие пустот и трещин. Образование указанных пороков, является признаком старения полимера [14]. Указанные пороки также были обнаружены при изучении интерференционной картины ПЭ нитей текстурированной пряжи.

Таким образом, апробация показала, что метод поляризационной микроскопии приемлем для оценки качества ПЭ волокон и нитей и выявления скрытых пороков полимера.

\section{6. Выводы}

1. Качество внутренней структуры ПЭ волокон (нитей) и выявление пороков, предложено оценивать по анализу интерференционной картины, наблюдаемой в поле зрения поляризационного микроскопа по следующим показателям:

- степень симметричности полос рисунка и однородность их окрашивания;

- цвет интерференционного окрашивания полос (пятен).

2. Оценку на соответствие качества выпускаемого ассортимента ПЭ волокон и элементарных нитей, рекомендовано проводить через сравнение интерференционной картины образца и контролируемого продукта.

\section{Литература}

1. Айзенштейн, Э. М. Мировое производство химических волокон [Текст] / Э. М. Айзенштейн // Рабочая одежда. Легкпромбизнес. - 2012. - № 2 (55). С. $18-19$.

2. Айзенштейн, Э. М. Полиэфирные волокна попрежнему в лидерах [Текст] / Э. М. Айзенштейн // Рабочая одежда. Легкпромбизнес. - 2012. - № 1 (54). C. $10-11$.

3. ГОСТ Р 53031-2008. Волокно хлопковое. Порядок измерения показателей на системе HVI [Текст] / Национальный стандарт Российской Федерации. Введен с 2010-01-01. - М: Стандартинформ, 2009. $11 \mathrm{c}$.

4. Испытательное оборудование для текстильных лабораторий [Электронный ресурс] / Режим доступа : http://pletmash.ru/wp-content/uploads/2013/09/MesdanLab_Catalogo_Russian.pdf - Загл. с экрана.

5. Текстильные волокна - источник розыскной и доказательной информации Ч II. Основные сведения об источниках микрообъектов - текстильных волокон [Текст] // Методики криминалистического исследования волокон. - Москва-Берлин: МВД СССР ВНИИ и МВД ГДР КИННП, 1982. - $184 \mathrm{c.}$

6. Скрипко, Г. О. Дослідження мікрооб'єктів волокнистої природи за допомогою поляризаційної мікроскопії [Текст] / Г. О. Скрипко. - Методичні рекомендації - Київ: ДНДЕКЦ МВС України, 2004. $42 \mathrm{c}$.

7. Скрипко, Г. О. Визначення видових ідентифікаційних ознак натуральних волокон, ідентифікація волокнистого складу ниток, текстильних матеріалів та виробів 3 них методом поляризаційної мікроскопії [Текст] / Г. О. Скрипко. - Методика - Київ: ДНДЕКЦ МВС України, 2012 - 40 с.

8. Калиновски, Е. Химические волокна (исследования и свойства) [Текст] / Е. Калиновски, Г. В. Урбанчик. - М.: Легкая индустрия, 1966. - 319 с.

9. Петухов, Б. В. Полиэфирные волокна [Текст] / Б. В. Петухов. - М.: Химия, 1976. - 271 с. 
10. Алешина, А. Л. Современные представления о строении целлюлоз [Текст] / А. Л. Алешина, С. В. Глазкова, Л. А. Луговская, М. В. Подойникова, А. Д. Фофанов, Е. В. Силина // Химия растительного сырья. -2001 . - № 1. - С. 5-36.

11. Кричевский, Г. Е. Методы исследования в текстильной химии. [Текст]: справ. / Г. Е. Кричевский, Ю. К. Овчинников, Г. Т. Хачатурова и др.; под общ. ред. Г. Е. Крического. - М., 1993. - 401 с.

12. Цой, Б. Разрушение тонких полимерных пленок и волокон [Текст]: учеб. пос. / Б. Цой, Э. М. Карташов, В. В. Шевелев, А. А. Валишин. - М.: Химия, 1997. - 344 с.

13. Маракушев, А. А. Петрология I. Основы кристаллооптики и породообразующие минералы [Текст] / А. А. Маракушев, А. В. Бобров, Н. Н. Перцев, А. Н. Феногенов. - М.: Научный Мир, 2000. - 316 с.

14. Кулигина, М. С. Действие света и атмосферных условий на ткани из смеси полиэфирных и целлюлозных волокон [Текст]: дис. ... канд. техн. наук: 05.19 .03 / М. С. Кулигина. - Москва-Иваново, 1968. $134 \mathrm{c}$.

\section{References}

1. Aizenshtein, E. M. (2012). Mirovoe proizvodstvo khimicheskih volokon [Global manufacturing of chemical fibers]. Working clothes. Legkprombiznes, 2 (55), 18-19.

2. Aizenshtein, E. M. (2012). Poliefirnye volokna poprezhnemu $\mathrm{v}$ liderah [Polyester fibers are still in the lead]. Working clothes. Legkprombiznes, 1 (54), 10-11.

3. Volokno khlopkovoe. Poriadok izmerenia pokazateley na sisteme HVI. National State Standard of Russia 53031-2008 [Cotton fiber. Indexes measuring procedure on the HVI system. National State Standard of Russia 53031-2008] (2009). Moscow: Standartinform, 7.

4. Ispytatelnoe oborudovanie dlia tekstilnyh laboratoriy [Test facilities for textile laboratories]. Available at: http://pletmash.ru/wp-content/uploads/2013/09/ MesdanLab Catalogo Russian.pdf

5. Tekstilnye volokna - istochnik rozysknoi i dokazatelnoi informatsii Ch. II. Osnovnye svedeniya ob istochnikah mikroobektov - tekstilnyh volokon. Metodiki kriminalisticheskogo issledovaniya volokon [Textile fibers the source of investigative and evidentiary information Pt. II. Main information about the sources of micro objects textile fibers. The methods of forensic researches of fibers]
(1982). Ministry of Internal Affairs of USSR All-Russian Scientific and Research Institute and Ministry of Internal Affairs of GDR KINNP. Moscow-Berlin, 184.

6. Skrypko, G. O. (2004). Doslidzhennia mikroobektiv voloknystoi pryrody za dopomogoiu poliaryzatsiynoi mikroskopii [Research of fibrous structure micro objects using polarization microscopy]. Methodical recommendations. Kyiw: DNDEKTS Ministry of Internal Affairs of Ukraine, 42.

7. Skrypko, G. O. (2012). Vyznachennia vydovyh identyfikatsiynyh oznak naturalnyh volokon, identifikatsiya voloknystogo skladu nytok, tekstylnyh materialiv ta vyrobiv $\mathrm{z}$ nyh metodom poliaryzatsiynoi mikroskopii [Determination of specific and identification features of natural fibers, identification of fibrous structure of yarns, textile materials and products from them using polarization microscopy]. Methodology. Kyiw: DNDEKTS Ministry of Internal Affairs of Ukraine, 40.

8. Kalinivski, E. (1966). Khimicheskie volokna (issledovaniya I svoistva) [Chemical fibers (researches and features)]. Moscow: Legkaya industria, 319.

9. Petuhov, B. V. (1976). Poliefirnye volokna [Polyester fibers]. Moscow: Khimiya, 271.

10. Aleshina, A. L., Glazkova, S. V., Lugovskaia, L. A., Podoynikova, M. V., Fofanov, A. D., Silina, E. V. (2001). Sovremennye predstavlenia o stroenii tselliuloz [Modern conceptions about the structure of cellulose]. Chemistry of vegetal resources, 1, 5-36.

11. Krichevskii, G. E., Ovchinnikov, Yu. K., Khacaturova, G. T., Anisimova, A. G., Novorodskii, A. G. (1993). Metody issledovaniya $\mathrm{V}$ tekstilnoi khimii: Monografiya [Methods of research in textile chemistry: Monograph]. Moscow, 401.

12. Tsoi, B. (1997). Razrushenie tonkih polimernyh plenok i volokon: uchebnoe posobie [Discruption of thin polymer films and fibers: work-book]. Moscow: Chemistry, 344.

13. Petrologiya, I. (2000). Osnovy kristalooptiki i porodoobrazuyushchie mineraly [Theory of crystal optics and rock-forming minerals]. Moscow: Scientific worls, 316.

14. Kuligina, M. S. (1968). Deistvie sveta i atmosfernyh usloviy na tkani iz smesi poliefirnyh i tselliuloznyh volokon [The effect of light and atmosphere conditions on textiles from the mixture of polyester and cellulose fibers]. Moscow-Ivanovo, 134.

Скрипко Галина Алексеевна, кандидат технических наук, ведущий эксперт, Научно-исследовательский экспертно-криминалистический центр при УМВД Украины в Николаевской области, ул. Акима, 2-а, г. Николаев, Украина, 54003

E-mail: mikroskop56@mail.ru 